\title{
Intravitreal Clindamycin and Dexamethasone Combined with Systemic Oral Antitoxoplasma Therapy versus Intravitreal Therapy Alone in the Management of Toxoplasma Retinochoroiditis: A Retrospective Study
}

\author{
Ashraf Bor'i $\mathbb{D}^{D}$, Ashraf Mahrous, Mahmoud A. Al-Aswad, Haitham Y. Al-Nashar $\mathbb{D}^{\mathrm{D}}$, \\ Waled M. Nada, Mostafa Wagih, Ahmed M. B. Awad, and Wael M. El-Haig
}

Department of Ophthalmology, Zagazig University, Zagazig, Egypt

Correspondence should be addressed to Ashraf Bor’i; ashborai@yahoo.com

Received 18 August 2017; Revised 7 December 2017; Accepted 3 January 2018; Published 12 February 2018

Academic Editor: Enrico Peiretti

Copyright ( 2018 Ashraf Bor'i et al. This is an open access article distributed under the Creative Commons Attribution License, which permits unrestricted use, distribution, and reproduction in any medium, provided the original work is properly cited.

Purpose. To compare clinical outcome of IVCD combined with oral therapy with IVCD alone in patients with toxoplasmic retinochoroiditis. Patients and Methods. Thirty eyes were reviewed. Two equal groups were identified (15 eyes each). Clinical outcome measures were resolution of active inflammation, changes in BCVA and CMT, adverse drug reactions, and rate of recurrence. Results. Mean baseline of BCVA $1.08 \pm 0.17$ and $1.03 \pm 0.15$ improved to $0.64 \pm 0.18$ and $0.69 \pm 0.17$ at the end of follow-up in group I and II, respectively. No statistically significant difference was observed. CMT was $392.6 \pm 33.16 \mu \mathrm{m}$ and $397.3 \pm 14.6 \mu \mathrm{m}$ significantly decreased to $314.7 \pm 4.43 \mu \mathrm{m}$ and $319.6 \pm 7.8 \mu \mathrm{m}$. Resolution of acute inflammation was achieved in all cases in both groups. There were no recurrent cases in group I, and only one out of 15 (6.7\%) in group II. No ocular or systemic adverse events were recorded. Conclusion. IVCD is an effective route of treatment for active toxoplasmic retinochoroiditis that can be used solely without the need to use systemic medications.

\section{Introduction}

Toxoplasmosis, caused by Toxoplasma gondii (T. gondii), is the most common infection of the retina in general populations worldwide.

T. gondii infection is responsible for the majority of infectious uveitis cases $[1,2]$. This disease typically affects the posterior pole of one eye, and lesions can present as either solitary, multiple, or satellite in nature, or as a pigmented retinal scar. Active lesions present as gray-white foci of retinal necrosis with adjacent choroiditis, vasculitis, hemorrhage, and vitritis. Cicatrization progresses from the periphery towards the center, with variable pigmentary changes. Anterior uveitis is another common finding, presenting with mutton-fat keratic precipitates, anterior chamber cells and flare, and posterior synechiae [3-5].
The diagnosis of ocular toxoplasmosis typically depends on clinical findings. When clinical diagnosis through fundus examination cannot be established with certainty, polymerase chain reaction could be ordered to look for antitoxoplasmosis antibody in ocular fluids. This test has shown high specificity and sensitivity to confirm the diagnosis $[6,7]$.

Ocular toxoplasmosis therapy includes the administration of antimicrobial drugs with or without the use of corticosteroids. Several drugs have been proposed for treatment, including pyrimethamine, sulfadiazine, spiramycin, clindamycin, and trimethoprim-sulfamethoxazole [8].

The most common side effects were associated with pyrimethamine medication and included hematologic complications, such as thrombocytopenia and leucopenia, despite folinic acid supplementation [9]. 
Intravitreal clindamycin injection and possibly steroids may be indicated for patients who have contraindications for systemic therapy specific against toxoplasmosis $[10,11]$.

The aim of this study was to compare the efficacy of intravitreal clindamycin and dexamethasone (IVCD) plus systemic oral antitoxoplasma therapy against that of intravitreal therapy alone in the treatment of active toxoplasmic retinochoroiditis.

\section{Patients and Methods}

This retrospective study reviewed the hospital records of thirty patients with active ocular toxoplasmic retinochoroiditis diagnosed and received treatment during the period starting from May 2014 to June 2017. The study was carried out according to the WMA Declaration of Helsinki-Ethical Principles for Medical Research Involving Human Subjects. All cases were clinically diagnosed as active toxoplasmic retinochoroiditis. Measurement of best corrected visual acuity (BCVA) and colored fundus photography were done for all patients. Both fundus fluorescein angiography and spectral domain optical coherence tomography (Spectralis, Heidelberg Engineering $\mathrm{GmbH}$ ) studies were performed if the ocular media were sufficiently clear for imaging.

Two groups of patients, with active toxoplasmic chorioretinitis in retinal zone 1, were identified. 15 eyes (15 patients) received treatment in the form of intravitreal injection combined with systemic treatment-group I (Figure 1). 15 eyes (15 patients) received intravitreal treatment alone without any systemic treatment-group II (Figure 2). Combination therapy was administered in group I with the intent to maximize the therapeutic effect.

Intravitreal injections were done under complete aseptic conditions. Two drugs were injected: clindamycin at a concentration of $1 \mathrm{mg} / 0.1 \mathrm{ml}$ and dexamethasone at a concentration of $400 \mu \mathrm{g} / 0.1 \mathrm{ml}$.

Patients in group I received systemic multidrug therapy combined with intravitreal treatment. The systemic multidrug therapy included pyrimethamine, sulfadiazine, and prednisolone.

Pyrimethamine was taken as a loading dose of $100 \mathrm{mg}$ on the first day and followed by a dose of $25 \mathrm{mg}$, twice daily, for 6 weeks. Sulfadiazine was taken as a dose of $1 \mathrm{~g}, 4$ times daily for 6 weeks. Prednisolone was taken as a dose of $60 \mathrm{mg} /$ day for 2 weeks and then was tapered gradually.

Patient data at 3, 6, and 12 months after initiation of treatment were collected. The main clinical outcome measures were resolution of active inflammation, changes in BCVA expressed in LogMAR units, changes in central macular thickness measured by OCT, adverse drug reactions, and the rate of recurrence of the inflammation during follow-up.

Statistical analysis of the data was performed using the Student $t$-test, and $p$ value determination ( $p$ value $<0.05$ was considered significant) and ( $p$ value $>0.05$ was considered insignificant).

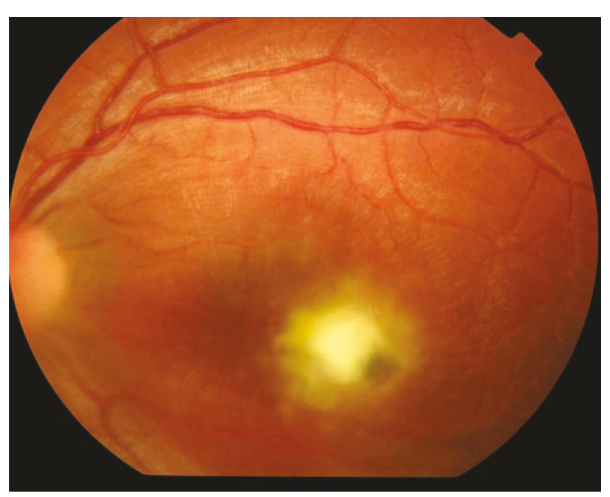

Figure 1: Group I (pretreatment).

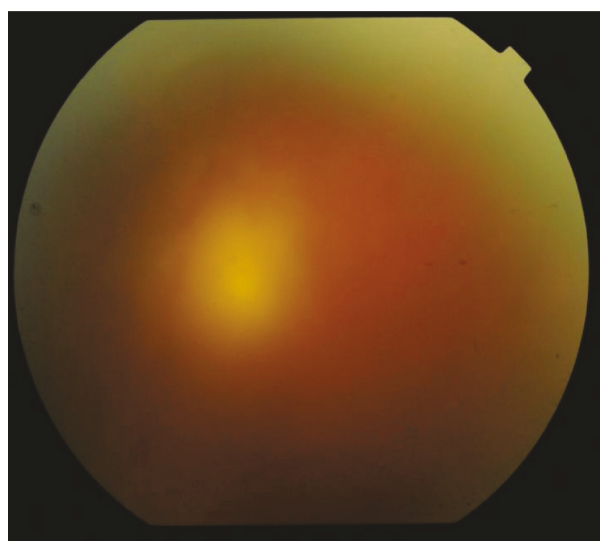

Figure 2: Group II (pretreatment).

\section{Results}

Thirty eyes of thirty patients with active toxoplasmic retinochoroiditis were treated either by intravitreal and systemic medications (15 eyes of 15 patients) or by only intravitreal medications (15 eyes of 15 patients).

The demographic data revealed that the mean age was $36.35 \pm 6.29$ years in group I and $35.55 \pm 4.19$ years in group II $(p=0.36)$; male to female ratio was 1.33 in group I and 1.5 in group II which was statistically insignificant.

In group I, mean baseline BCVA was $1.08 \pm 0.17$ LogMAR units; it improved to $0.8 \pm 0.19$ at the 3 rd-month follow-up visit and to $0.72 \pm 0.11$ and $0.64 \pm 0.18$ at the 6th-month and the 12th-month follow-up visits, respectively. The difference was statistically significant at the last follow-up visit as compared to baseline value $(p<0.05)$.

In group II, mean baseline BCVA was $1.03 \pm 0.15$ LogMAR units, BCVA values improved to $0.87 \pm 0.21$ at the 3rd-month follow-up visit and to $0.75 \pm 0.09$ and $0.69 \pm 0.17$ at the 6th-month and the 12th-month visits, respectively. The difference was statistically significant at the last followup visit as compared to the pretreatment BCVA $(p<0.05)$.

No statistically significant difference was observed between group I and group II $(p>0.05)$ during the followup period (Table 1; Figure 3).

In group $\mathrm{I}$, the mean central macular thickness (CMT) before treatment was $392.6 \pm 33.16 \mu \mathrm{m}$ while in 
TABLE 1: BCVA (LogMAR) in both groups.

\begin{tabular}{lcccc}
\hline & Pretreatment & 3rd month & 6th month & 12th month \\
\hline Group I & $1.08 \pm 0.17$ & $0.80 \pm 0.19$ & $0.72 \pm 0.11$ & $0.64 \pm 0.18$ \\
Group II & $1.03 \pm 0.15$ & $0.87 \pm 0.21$ & $0.75 \pm 0.09$ & $0.69 \pm 0.17$ \\
$p$ value & 0.8 & 0.7 & 0.5 & 0.8 \\
\hline
\end{tabular}

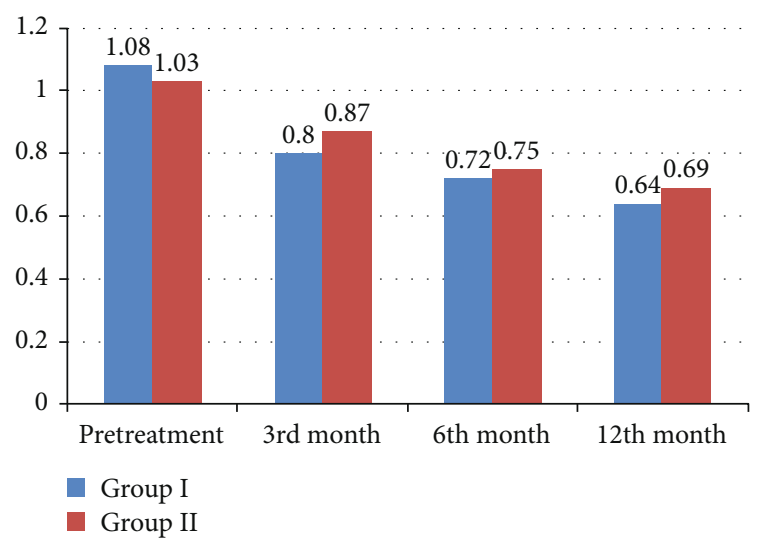

FIgURE 3: BCVA measured by LogMAR in patients of both groups.

group II, it was $397.3 \pm 14.6 \mu \mathrm{m}$ (no statistically significant difference, $p>0.05$ ).

In group I, CMT decreased to $332.7 \pm 8.2 \mu \mathrm{m}$ at the 3rd-month of follow-up visit and to $321.8 \pm 11.2 \mu \mathrm{m}$ and $314.7 \pm 4.43 \mu \mathrm{m}$ at the 6th-month and the 12th-month visits, respectively. The difference was statistically significant at the last follow-up visit as compared to the baseline thickness $(p<0.05)$.

While in group II, CMT improved to $340.9 \pm 5.2 \mu \mathrm{m}$ at the 3rd-month of follow-up visit and to $325.9 \pm 15.6 \mu \mathrm{m}$ and $319.6 \pm 7.8 \mu \mathrm{m}$ at the 6th-month and the 12th-month visits, respectively. The difference was statistically significant at the last follow-up visit as compared to the baseline thickness $(p<0.05)$.

There was no statistically significant difference observed between group I and group II $(p>0.05)$ during the followup period (Table 2; Figure 4).

Resolution of acute inflammation was achieved in all cases in both groups (Figures 5 and 6). To control the intraocular inflammation, the mean number of injections was 1.4 (range: 1-3 injections) with a mean interval of $19.4 \pm 4.1$ days in group $I$ and the mean number of injections was 1.7 (range: 1-4 injections), with a mean interval of $17.6 \pm 3.2$ days in group II. There was no statistically significant difference observed between group I and group II during the follow-up period $(p=0.3)$.

The incidence of recurrent toxoplasmic retinochoroiditis in patients during the follow-up period was 0 out of $15(0 \%)$ in group I and 1 out of 15 (6.7\%) in group II. There was no statistically significant difference observed between group I and group II during the follow-up period $(p=0.2)$.

No ocular or systemic adverse events were observed in both groups.
TABLE 2: Central macular thickness (CMT) measured by OCT in both groups.

\begin{tabular}{lcccc}
\hline & Pretreatment & 3rd month & 6th month & 12th month \\
\hline Group I & $392.6 \pm 33.16$ & $332.7 \pm 8.2$ & $321.8 \pm 11.2$ & $314.7 \pm 4.43$ \\
Group II & $397.3 \pm 14.6$ & $340.9 \pm 5.2$ & $325.9 \pm 15.6$ & $319.6 \pm 7.8$ \\
$p$ value & 0.6 & 0.5 & 0.5 & 0.7 \\
\hline
\end{tabular}

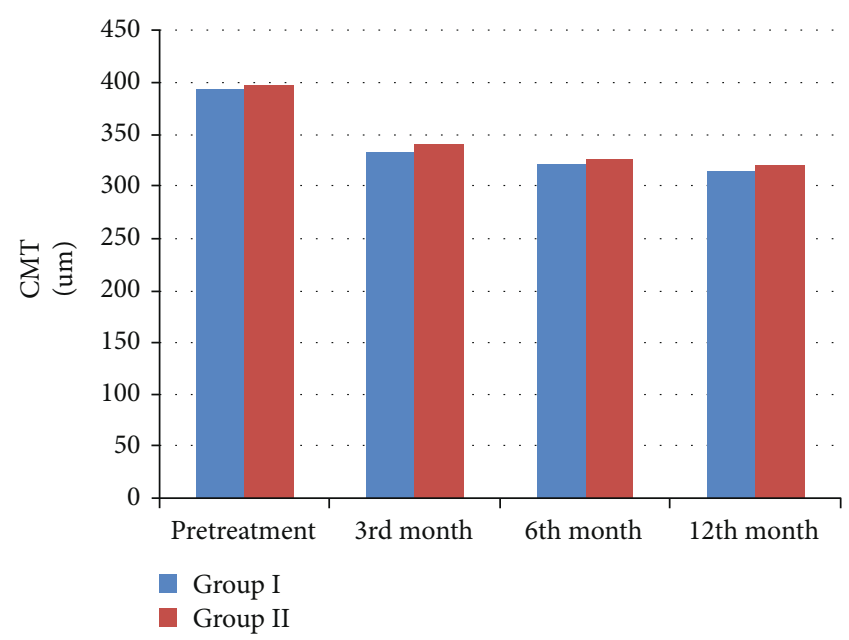

FIgURE 4: CMT measured by OCT in both groups.

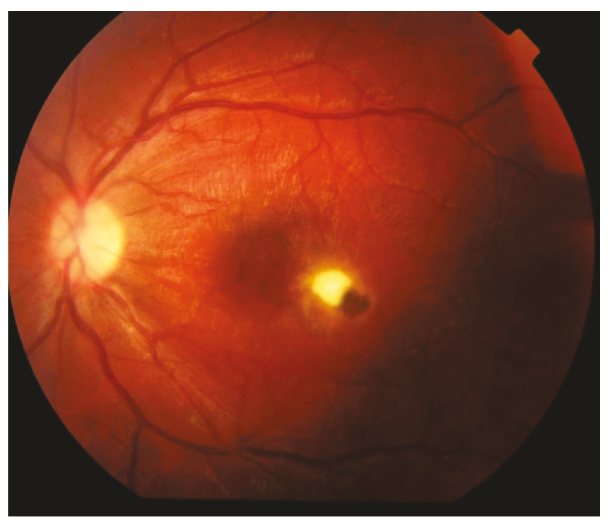

Figure 5: Group I (posttreatment).

\section{Discussion}

Toxoplasmosis is the most common cause of intraocular inflammation in the world. Ocular toxoplasmosis is a potentially blinding condition and is associated with severe morbidity [12]. Ocular toxoplasmosis therapy includes the administration of antimicrobial drugs with or without corticosteroids. Several drugs have been proposed for treatment including pyrimethamine, sulfadiazine, spiramycin, clindamycin, and trimethoprim-sulfamethoxazole [13].

Compliance remains an important issue, as the treatment often requires many pills daily. Monitoring of blood cell counts is mandatory during the treatment, and patients must 


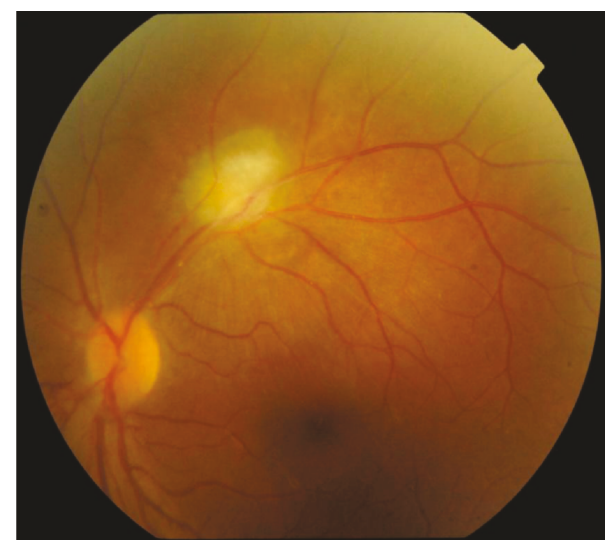

Figure 6: Group II (posttreatment).

be aware of the possible allergic reactions or other complications of systemic treatment [14].

The present study compared the combined intravitreal and systemic treatment with intravitreal injection alone in patients with ocular toxoplasmosis. Thirty eyes of thirty patients with active toxoplasmic retinochoroiditis were retrospectively reviewed. Two groups of patients were identified: group I was treated with a combined intravitreal and systemic therapy regimen, while group II was treated with intravitreal injection alone. All patients were followed up for 12 months.

In group I, the mean baseline BCVA improved from $1.08 \pm 0.17$ before the treatment to $0.64 \pm 0.18$ at the 12th-month follow-up visit. In group II, the mean baseline BCVA improved from $1.03 \pm 0.15$ to $0.69 \pm 0.17$, with no significant difference observed between the two groups at the end of the follow-up period.

These data are in agreement with Soheilian et al., [15] who compared the efficacy of the classical treatment of ocular toxoplasmosis (pyrimethamine, sulfadiazine, and prednisolone) with a regimen consisting of trimethoprim/ sulfamethoxazole (cotrimoxazole) plus prednisolone. They found that BCVA after treatment was 0.12 (LogMAR) in the classical treatment group and 0.09 (LogMAR) in the trimethoprim/sulfamethoxazole treatment group, with no significant difference observed $(p=0.56)$.

Lasave et al., [16] reported the anatomic and functional outcomes of intravitreal clindamycin and dexamethasone treatment of toxoplasmic retinochoroiditis. They reported that the baseline BCVA improved from a value of $1 \pm 0.4$ to $0.5 \pm 0.4$ at the end of the follow-up period. They also reported a significant reduction in CMT by OCT from $387.6 \pm 70.1 \mu \mathrm{m}$ to $185.2 \pm 44.7 \mu \mathrm{m}$ after a 24-month follow-up period. They observed that resolution of toxoplasmic retinochoroiditis was achieved in all cases with a mean number of injections of 3.6 (range $=2-5$ injections) and a mean interval of $15.5 \pm 4$ days. In comparison to the present study, the mean CMT before treatment was $392.6 \pm 33.16 \mu \mathrm{min}$ in group I and $397.3 \pm 14.6 \mu \mathrm{min}$ in group II, and those measurements decreased to 314.7 $\pm 4.43 \mu \mathrm{m}$ in group I and to $319.6 \pm 7.8 \mu \mathrm{m}$ in group II at the 12 th-month follow-up visits. There is no significant difference between the groups during the follow-up period. Resolution of acute inflammation was achieved in all cases and in both groups with a mean number of injections of 1.4 in group I and 1.7 in group II $(p=0.3)$.

Choudhury et al., [17] studied the role of intravitreal trimethoprim/sulfamethoxazole in the treatment of toxoplasmic retinochoroiditis and found that there is no evidence of retinal toxicity in all patients. They concluded that the combined intravitreal trimethoprim/sulfamethoxazole and dexamethasone treatment might be an alternative strategy in patients with toxoplasmic retinochoroiditis.

Felix et al. [18] compared the effects of trimethoprimsulfamethoxazole treatment versus a placebo in reducing the risk of toxoplasmic retinochoroiditis recurrences. They found that the incidence of recurrence within 12 months was 0 out of $46(0 \%)$ and 6 out of $47(12.80 \%)$ in the trimethoprim-sulfamethoxazole and placebo-treated groups, respectively $(p=0.26)$. These data are comparable with this study where the incidence of toxoplasmic retinochoroiditis recurrence within 12 months of follow-up was 0 out of $15(0 \%)$ in group I and lout of $15(6.7 \%)$ in group II with no significant difference observed between the two groups $(p=0.2)$.

\section{Conclusions}

It can be concluded from this study that repeated intravitreal injection of clindamycin and dexamethasone is an effective regimen of treatment for active toxoplasmic retinochoroiditis, sparing patients from the burden of daily intake of multiple oral medications and their possible adverse effects. However, this study has the limitation of being retrospective wherein the baseline state, the intervention, and outcome were obtained from already existing data.

\section{Conflicts of Interest}

The authors have no conflict of interest to declare.

\section{References}

[1] A. L. Vallochi, C. Muccioli, M. C. Martins, C. Silveira, R. Belfort Jr., and L. V. Rizzo, "The genotype of Toxoplasma gondii strains causing ocular toxoplasmosis in humans in Brazil," American Journal of Ophthalmology, vol. 139, no. 2, pp. 350-351, 2005.

[2] G. N. Holland, "Ocular toxoplasmosis: a global reassessment, part I: epidemiology and course of disease," American Journal of Ophthalmology, vol. 136, no. 6, pp. 973-988, 2003.

[3] E. Antoniazzi, R. Guagliano, V. Meroni, S. Pezzotta, and P. E. Bianchi, "Ocular impairment of toxoplasmosis," Parasitologia, vol. 50, pp. 35-36, 2008.

[4] U. Pleyer, N. Torun, and O. Liesenfeld, "Ocular toxoplasmosis," Der Ophthalmologe, vol. 104, no. 7, pp. 603-616, 2007.

[5] M. J. Nóbrega and E. L. Rosa, “Toxoplasmosis retinochoroiditis after photodynamic therapy and intravitreal triamcinolone for a supposed choroidal neovascularization: a case report," Arquivos Brasileiros de Oftalmologia, vol. 70, no. 1, pp. 157$160,2007$. 
[6] T. W. Harper, D. Miller, J. C. Schiffman, and J. L. Davis, "Polymerase chain reaction analysis of aqueous and vitreous specimens in the diagnosis of posterior segment infectious uveitis," American Journal of Ophthalmology, vol. 147, no. 1, pp. 140-147.e2, 2009.

[7] A. Rothova, J. H. de Boer, N. H. ten Dam-van Loon et al., "Usefulness of aqueous humor analysis for the diagnosis of posterior uveitis," Ophthalmology, vol. 115, no. 2, pp. 306311, 2008.

[8] C. Silveira, R. Belfort Jr., C. Muccioli et al., "The effect of longterm intermittent trimethoprim/sulfamethoxazole treatment on recurrences of toxoplasmic retinochoroiditis," American Journal of Ophthalmology, vol. 134, no. 1, pp. 41-46, 2002.

[9] G. N. Holland, C. M. Crespi, N. ten Dam-van Loon et al., "Analysis of recurrence patterns associated with toxoplasmic retinochoroiditis," American Journal of Ophthalmology, vol. 145, no. 6, pp. 1007-1013.e1, 2008.

[10] F. B. Aggio, C. Muccioli, and R. Belfort Jr., "Intravitreal triamcinolone acetonide as an adjunct in the treatment of severe ocular toxoplasmosis," Eye, vol. 20, no. 9, pp. 1080-1082, 2006.

[11] L. Sobrin, L. I. Kump, and C. S. Foster, "Intravitreal clindamycin for toxoplasmic retinochoroiditis," Retina, vol. 27, no. 7, pp. 952-957, 2007.

[12] H. Talabani, T. Mergey, H. Yera et al., "Factors of occurrence of ocular toxoplasmosis. A review," Parasite, vol. 17, no. 3, pp. 177-182, 2010.

[13] K. Kishore, M. D. Conway, and G. A. Peyman, "Intravitreal clindamycin and dexamethasone for toxoplasmic retinochoroiditis," Ophthalmic Surgery and Lasers, vol. 32, no. 3, pp. 183-192, 2001.

[14] O. Backhouse, K. J. Bhan, and F. Bishop, "Intravitreal triamcinolone acetonide as an adjunct in the treatment of severe ocular toxoplasmosis," Eye, vol. 22, no. 9, pp. 1201-1202, 2008.

[15] M. Soheilian, M. M. Sadoughi, M. Ghajarnia et al., "Prospective randomized trial of trimethoprim/sulfamethoxazole versus pyrimethamine and sulfadiazine in the treatment of ocular toxoplasmosis," Ophthalmology, vol. 112, no. 11, pp. 1876-1882, 2005.

[16] A. F. Lasave, M. Díaz-Llopis, C. Muccioli, R. Belfort Jr., and J. F. Arevalo, "Intravitreal clindamycin and dexamethasone for zone 1 toxoplasmic retinochoroiditis at twenty-four months," Ophthalmology, vol. 117, no. 9, pp. 1831-1838, 2010.

[17] H. Choudhury, A. Jindal, A. Pathengay, A. Bawdekar, T. Albini, and H. W. Flynn, "The role of intravitreal trimethoprim/sulfamethoxazole in the treatment of toxoplasma retinochoroiditis," Ophthalmic Surg Lasers Imaging Retina, vol. 46, no. 1, pp. 137-140, 2015.

[18] J. P. F. Felix, R. P. C. Lira, R. S. Zacchia, J. M. Toribio, M. A. Nascimento, and C. E. L. Arieta, "Trimethoprim-sulfamethoxazole versus placebo to reduce the risk of recurrences of Toxoplasma gondii retinochoroiditis: randomized controlled clinical trial," American Journal of Ophthalmology, vol. 157, no. 4, pp. 762-766.e1, 2014. 


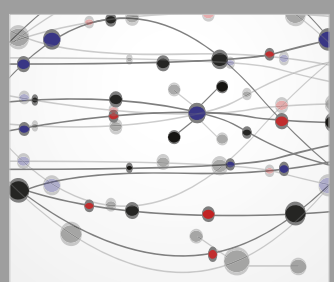

The Scientific World Journal
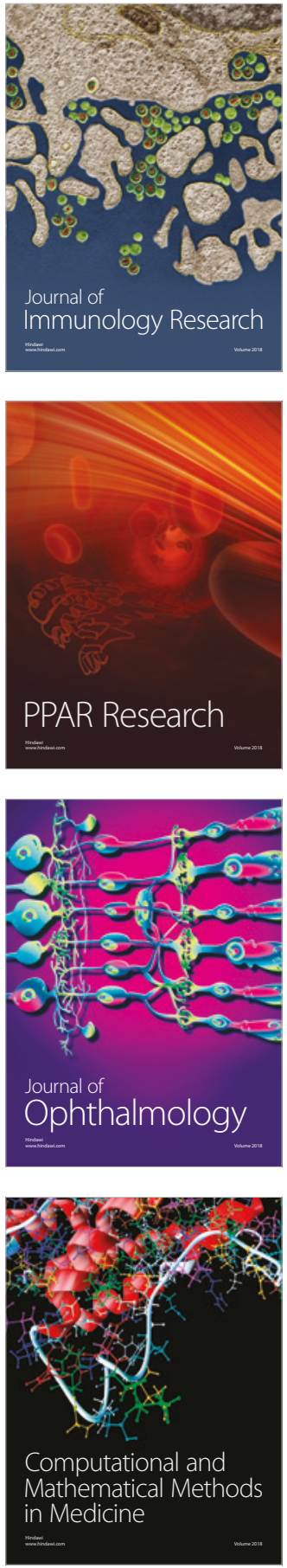

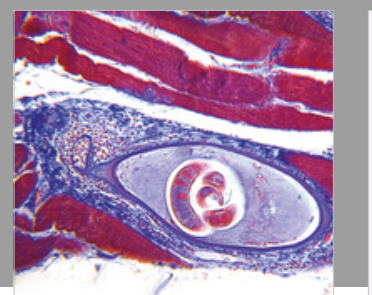

Gastroenterology Research and Practice

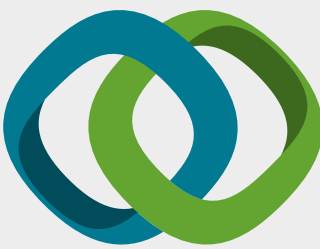

\section{Hindawi}

Submit your manuscripts at

www.hindawi.com
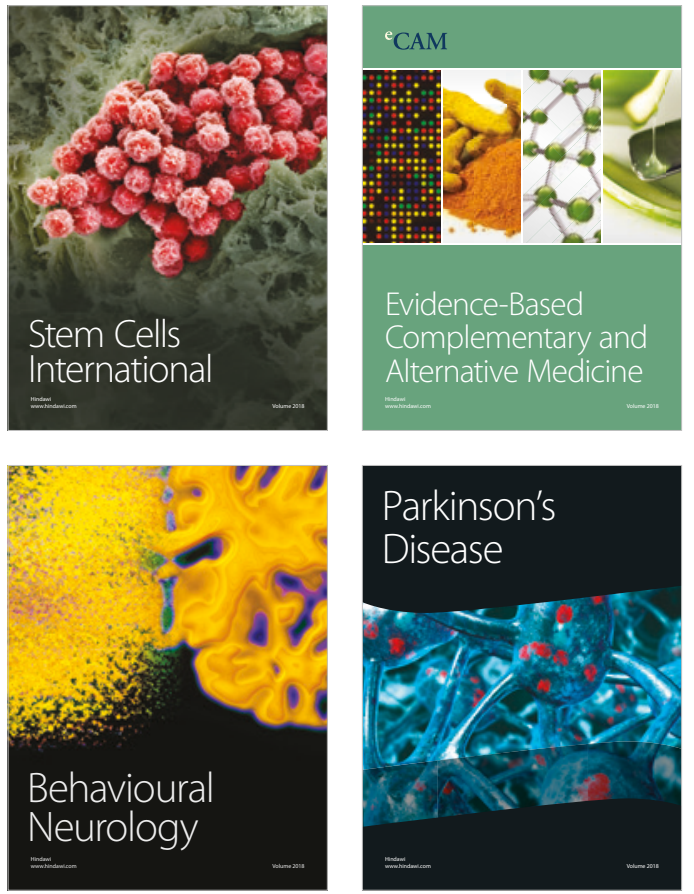

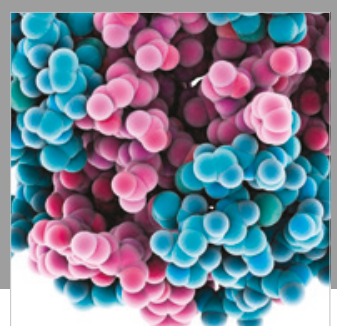

ournal of

Diabetes Research

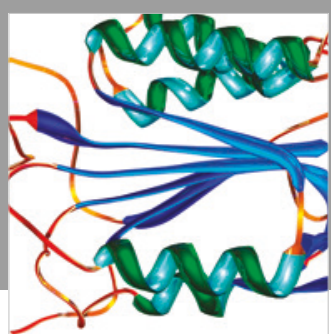

Disease Markers
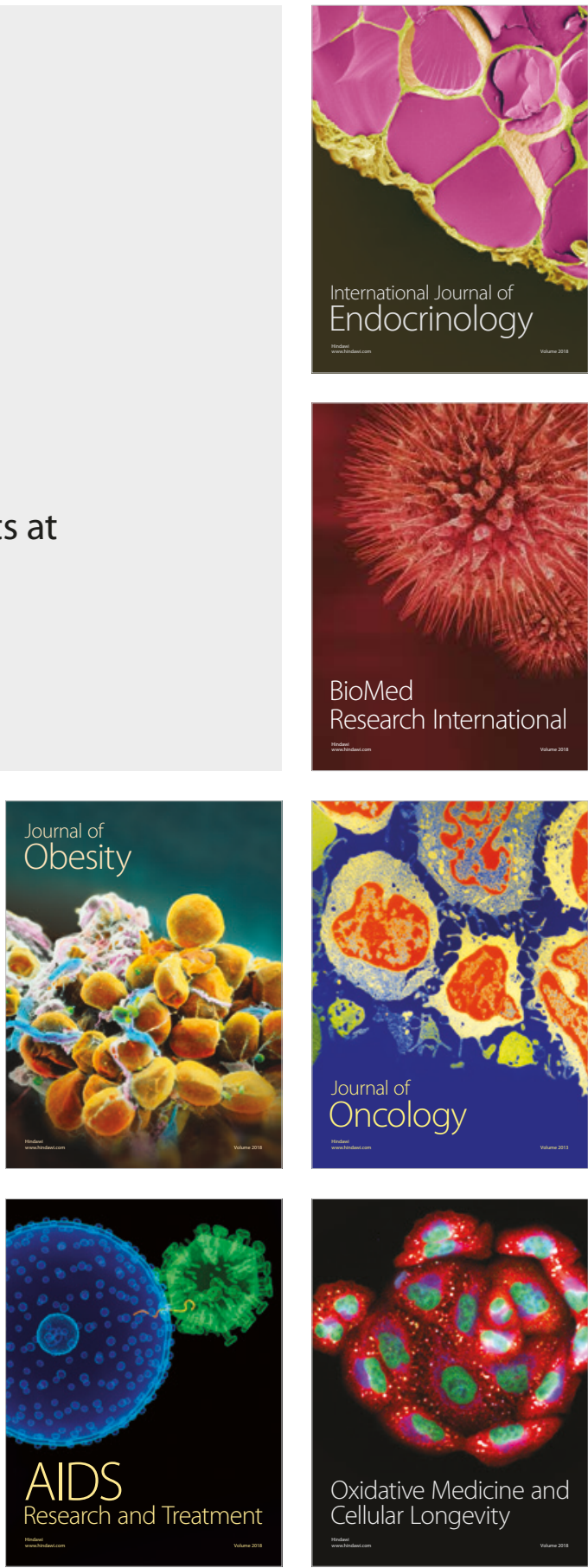